\title{
ЧЕЛОВЕЧЕСКИЙ КАПИТАЛ, КАК ЭТАП РАЗВИТИЯ СТРАТЕГИЧЕСКОГО ПЛАНИРОВАНИЯ В РФ (НАЦИОНАЛЬНЫЕ ПРОЕКТЫ «ДЕМОГРАФИЯ», «ОБРАЗОВАНИЕ»)
}

\author{
(c) 2021 Петров А. М. \\ доктор экономических наук, профессор Департамента бизнес-аналитики \\ Финансовый университет при Правительстве Российской Федерации, Россия, Москва \\ E-mail: palmi@inbox.ru
}

\begin{abstract}
Триггером использования стратегического подхода в государственном управлении выступило осознание того, что в настоящее время эффективное государственное управление требует перехода от приоритета краткосрочных целей к долгосрочному планированию решения сложных проблем, носящих комплексный характер, не ограниченных территориальными границами государства. Человеческий капитал, как этап развития стратегического планирования в РФ, в статье рассмотрен на основе национальных проектов - «Демография», «Образование».
\end{abstract}

Ключевые слова: человеческий капитал, здравоохранение, образование, демография, государственное стратегическое планирование.

Стратегической целью реализации 10 федеральных проектов, входящих в Национальный проект «Образование», представленных на рисунке 1 , является достижение глобальной конкурентоспособности образования в РФ посредством воспитания гармонично развитой и социально ответственной личности.

Выбор данной цели не является случайным благополучие населения любой страны в существенной степени зависит от уровня развития образования, каждый из уровней которого имеет свои отличительные характеристики, влияющие на основной фактор социально-экономического развития страны и инструмент привлечения инвестиций - человека.

В этой связи ФП, входящие в состав НП» Образование» направлены на обновление содержания образовательных программ, инфраструктуры, повышение уровня квалификации кадров, улучшение механизма управления образовательной сферой.

Так, например, ФП «Современная школа» направлен на выравнивание доступа к качественному образованию в общеобразовательных организациях; ФП «Успех каждого ребенка» - на формирование эффективной системы выявления, поддержки и развития детей и молодежи, обладающих талантом и проявляющих выдающиеся способности, в т.ч. за счет открытия детских технопарков; ФП «Поддержка семей, имеющих детей» - на экспертную и консультативную поддержку родителей.
Данные Индекса уровня образования 2019 (Education Index 2019), представляющего собой комбинированный показатель среднего количества лет обучения в школе для взрослых и ожидаемого количества лет обучения для детей, используемые для расчета Индекса человеческого развития (Human Development Index) в рамках Программы развития ООН, свидетельствуют о том, что РФ находится на 33 месте (на рисунке 2 представлены только те страны, которые опережают РФ по значению данного показателя).

При этом прослеживается положительная динамика изменения значения данного индекса в сравнении с 1990 г., что наглядно представлено на рисунке 3.

Таким образом, в большей части стран мирового пространства наблюдается рост числа и доли пожилых людей в численности их населении. Старение населения может стать одной из наиболее значительных социальных трансформаций XXI века, что отразится практически на всех секторах общества, включая рынки труда и финансов, спрос на товары и услуги, такие как жилье, транспорт и социальная защита, а также на связи поколений.

Согласно данным исследования World Population Prospects 2019, подготовленного Отделом народонаселения ООН, к 2050 г. каждым шестым человеком в мире будет являться человек старше 65 лет (16\% населения мира) (рисунок 4), тогда как в 2019 г. в данную категория входил каждый одиннадцатый человек (9\% населения 


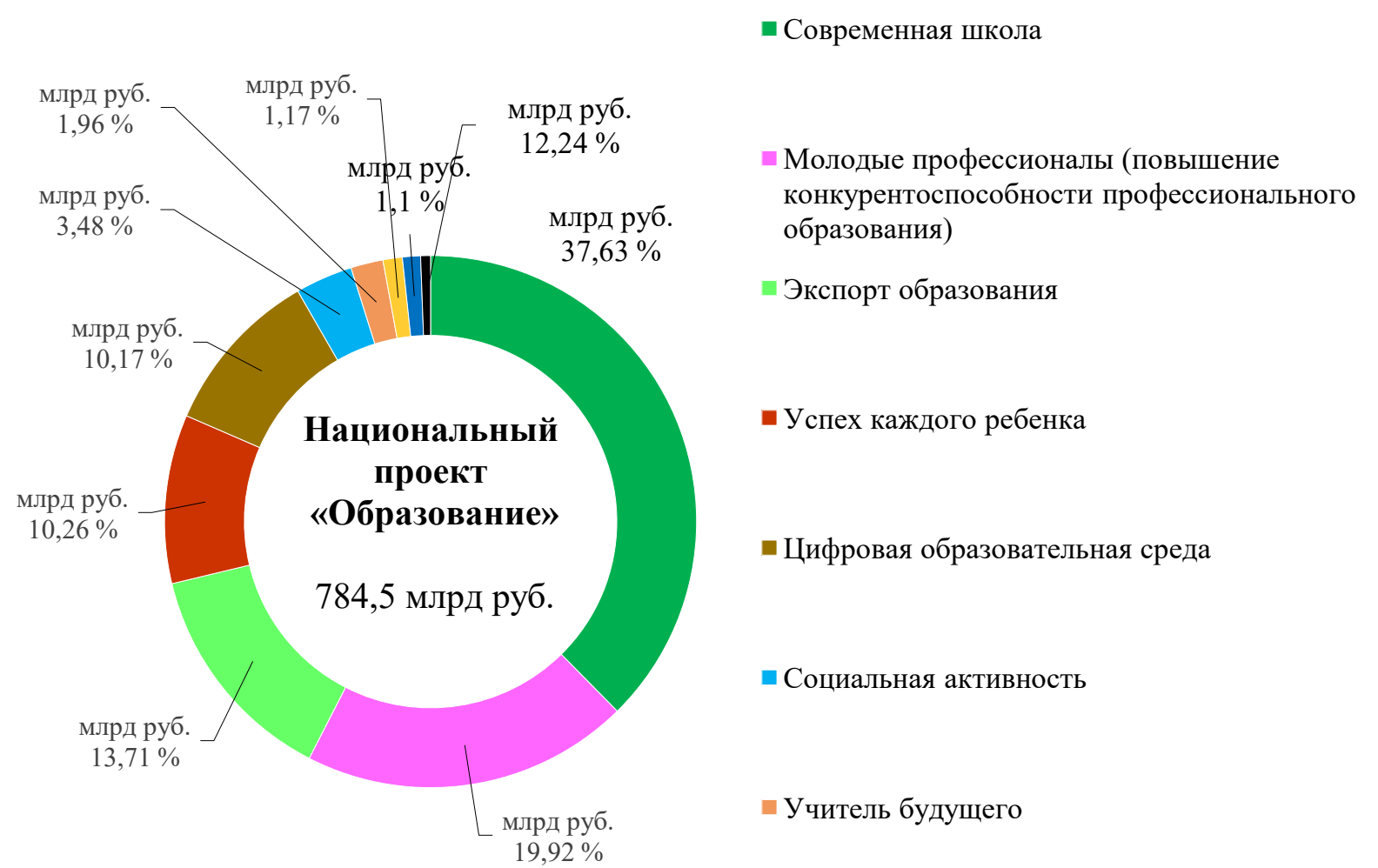

Рисунок 1. Общий объем финансирования федеральных проектов, входящих в состав национального проекта «Образование»

Источник: составлено по материалам [8].

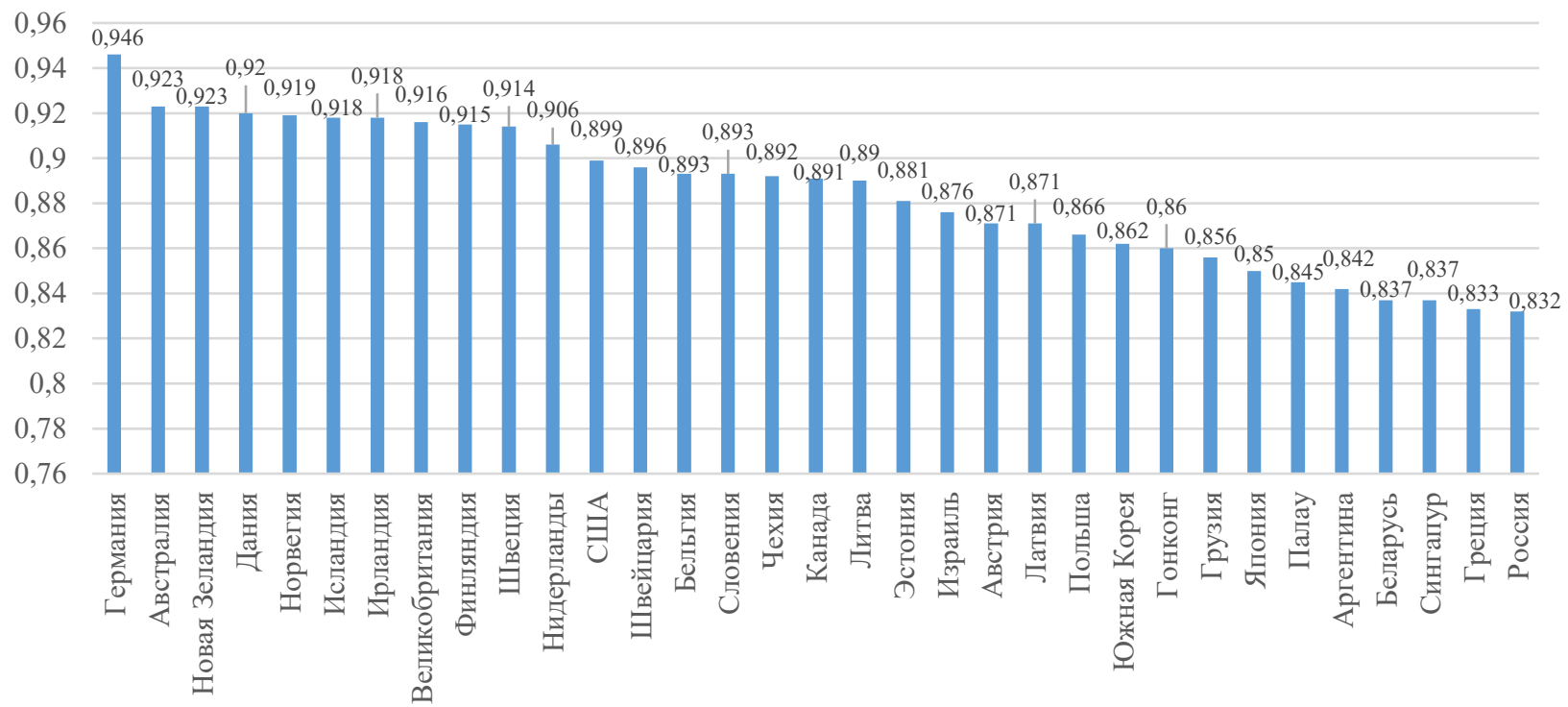

Рисунок 2. Индекс уровня образования 2019

Источник: составлено по материалам [9]. 


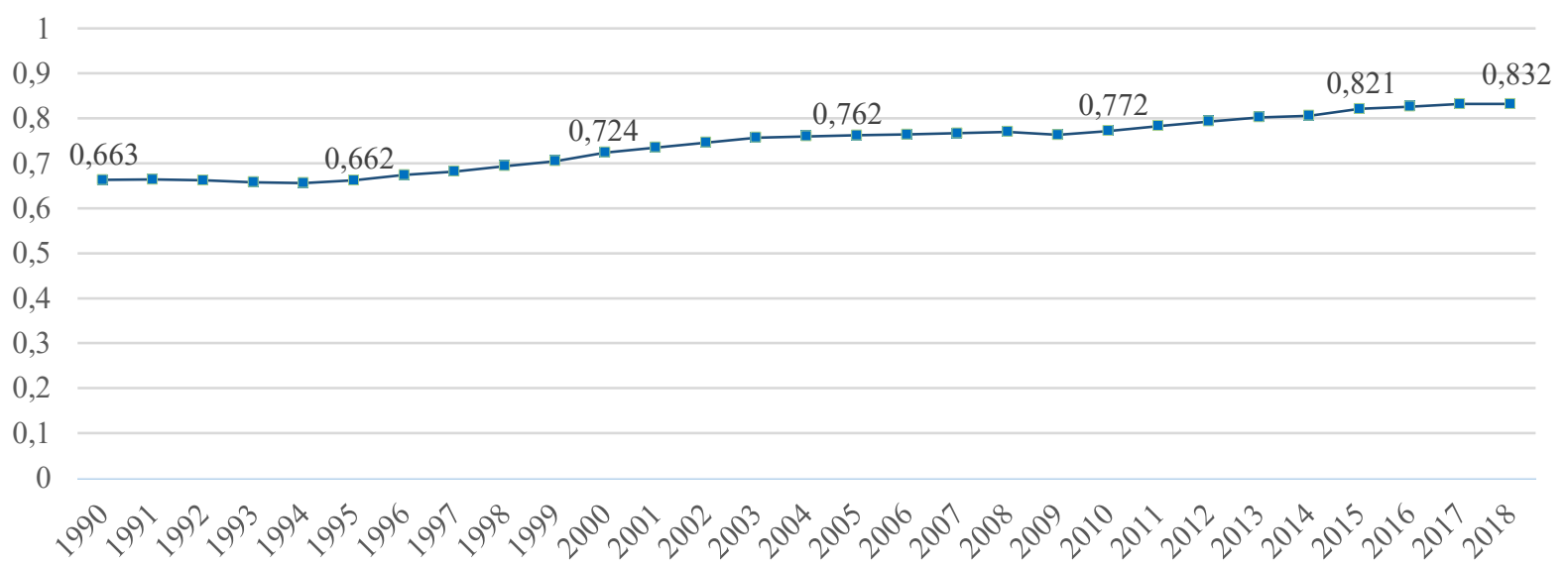

Рисунок 3. Индекс уровня образования Российской Федерации за период 1990-2018 гг. Источник: составлено по материалам [9].

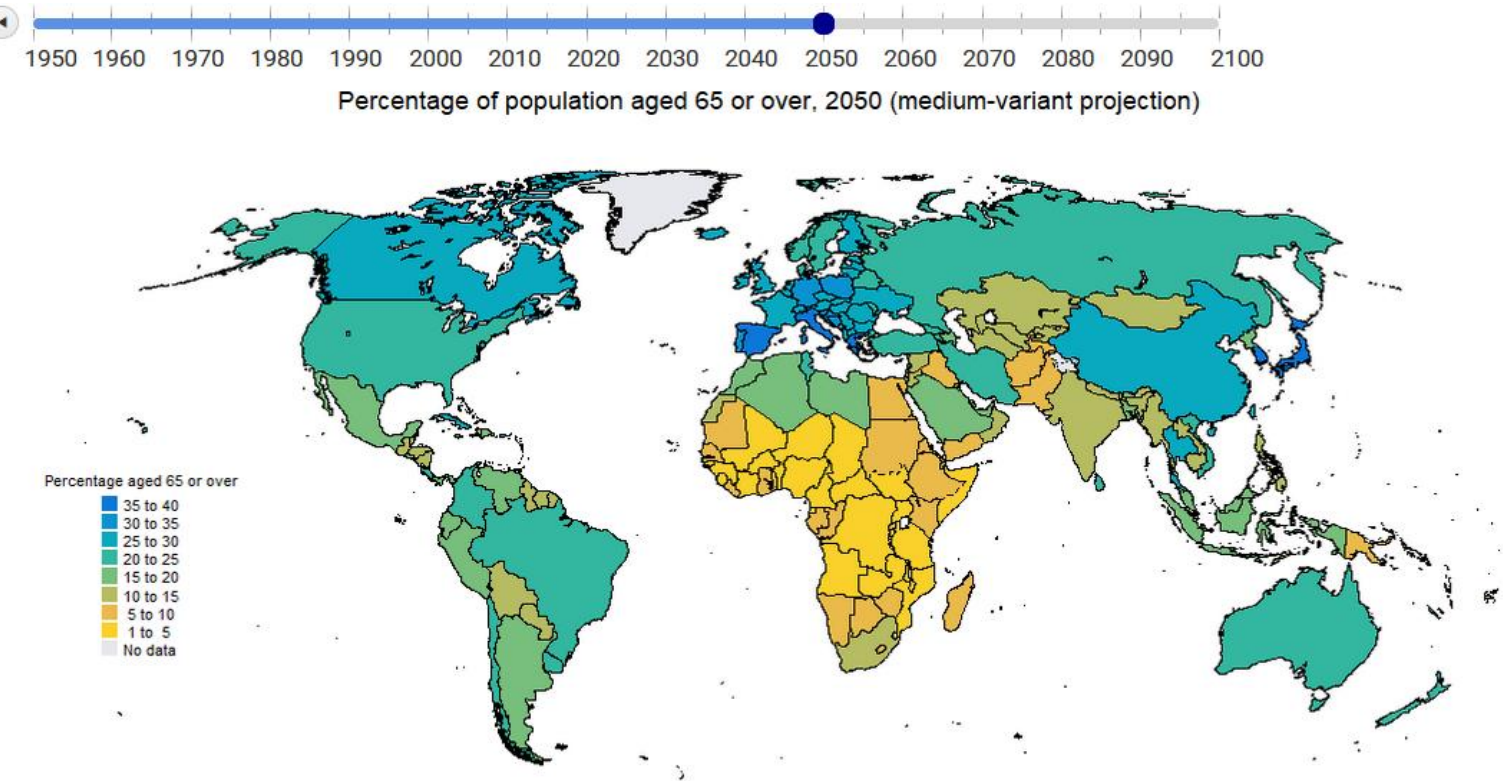

Рисунок 4. Прогноз доли людей в возрасте 65 лет и старше на период до 2050 г. Источник: Данные исследования World Population Prospects 2019 [11].

мира). К 2050 г. каждый четвертый человек, проживающий в Европе и Северной Америке, может быть в возрасте 65 лет и старше. Во многом это связано с тем, что в мире в 2018 г. численность населения в возрасте 65 лет и старше впервые в истории превысила численность детей в возрасте до 5 лет. Прогнозируется, что число людей в возрасте 80 лет и старше утроится: со 143 миллионов в 2019 г. до 426 миллионов в 2050 г. [10].

$\mathrm{B}$ соответствии с классификацией $\mathrm{OOH}$ население страны считается старым при достижении показателем численности населения страны в возрасте 65 лет и старше 7 процентов. Посколь- ку в РФ значение данного показателя за 2019 г. составляет 15,1\% [12], можно с уверенностью говорить о том, что решение демографических проблем является актуальной задачей для РФ на ближайшие годы (рисунок 5).

В этой связи в составе национального проекта «Демография» была предусмотрена реализация 5 федеральных проектов, представленных на рисунке 6, направленных как на стимулирование роста населения, так и на реализацию мер, поддерживающих и обеспечивающих рост трудоспособного населения, в том числе старшего поколения. 


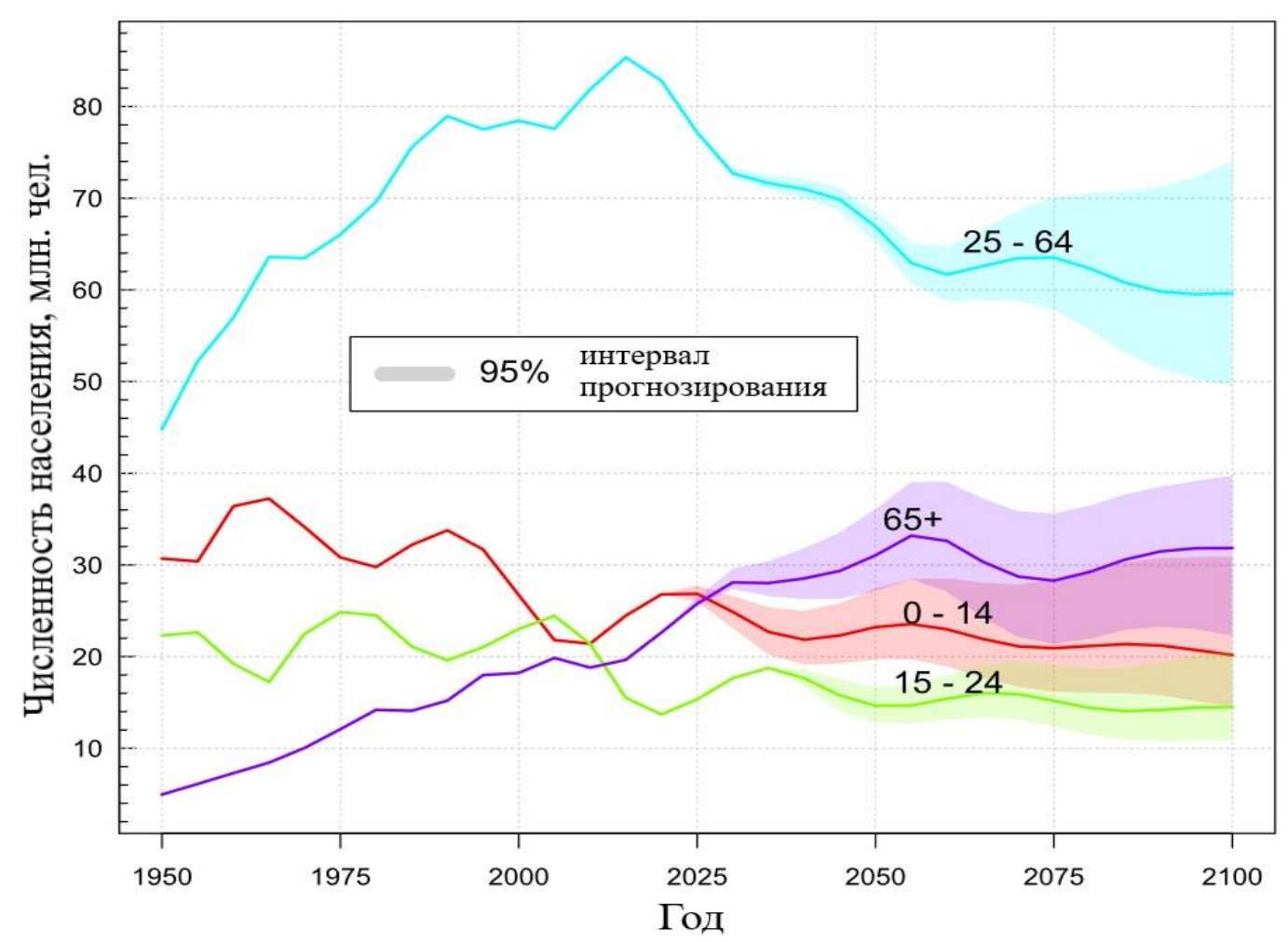

Рисунок 5. Прогноз структуры населения РФ с разбивкой по широким возрастным группам на период до 2100 г.

Источник: Материалы Департамента по экономическим и социальным вопросам ООН [13].

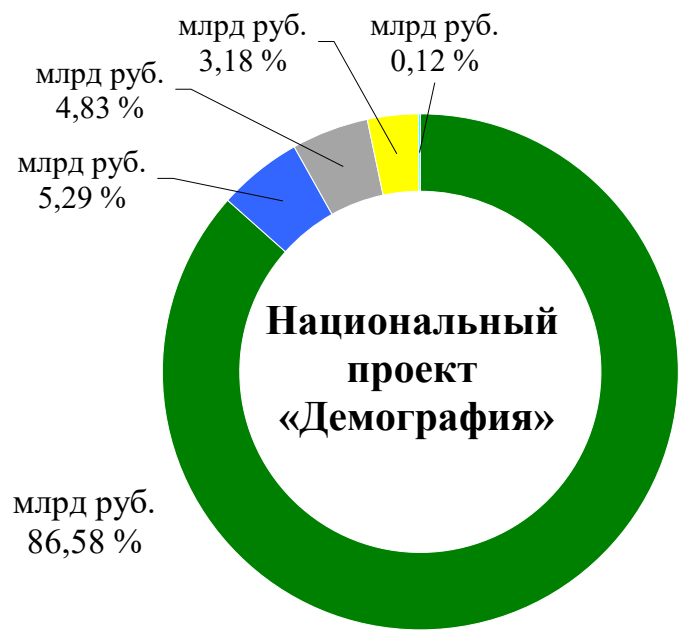

Финансовая поддержка семей при рождении детей

- Содействие занятости женщин - создание условий дошкольного образования для детей в возрасте до 3 лет

Спорт - норма жизни

Старшее поколение

Укрепление общественного здоровья

Рисунок 6. Общий объем финансирования федеральных проектов, входящих в состав национального проекта «Демография»

Источник: составлено по материалам [14]. 


\section{Библиографический список}

1. Указ Президента РФ от 07.05.2018 № 204 (ред. от 19.07.2018) «О национальных целях и стратегических задачах развития Российской Федерации на период до 2024 года» // СПС КонсультантПлюс.

2. Прямая линия с Владимиром Путиным // Президент России: официальный сайт. - 2019.-20 июня.- Текст: электронный. - URL: http://kremlin.ru/events/president/news/60795.

3. Основные документы // Всемирная организация здравоохранения: [сайт].- Текст: электронный.- URL: http://apps.who.int/gb/bd/PDF/bd48/basic-documents-48th-edition-ru.pdf?ua=1\#page=9.

4. Национальный проект «Здравоохранение» // Будущее России. Национальные проекты: [сайт].- Текст: электронный.- URL: https://futurerussia.gov.ru/zdravoohranenie.

5. Социальные детерминанты здоровья // Всемирная организация здравоохранения: [сайт].- Текст: электронный.-URL: https://www.who.int/topics/social_determinants/ru/.

6. Тяжкий труд, бедность и старость: три причины болезней в России // Всероссийский центр изучения общественного мнения: [сайт].- 2019.- 16 мая.- Текст: электронный.- URL: https://wciom.ru/index. php?id=236\&uid $=9687$.

7. Качество медицинских услуг: запрос на жесткий контроль // Всероссийский центр изучения общественного мнения: [сайт].- 2019.- 11 декабря.- Текст: электронный.- URL: https://wciom.ru/index. php?id=236\&uid=10067.

8. Национальный проект «Образование» // Будущее России. Национальные проекты: [сайт].- Текст: электронный. - URL: https://futurerussia.gov.ru/obrazovanie.

9. Human Development Indicators. Russian Federation // United Nations Development Programme: [сайт].- Текст: электронный.- URL: http://hdr.undp.org/en/indicators/103706\#.

10. World Population Prospects 2019 // United Nations: [сайт].- Текст: электронный._ URL: https://population. un.org/wpp/.

11. World Population Prospects 2019: Maps // United Nations: [сайт].- Текст: электронный.- URL: https:// population.un.org/wpp/Maps/.

12. World Population Prospects 2019. Demographic Profiles. Russian Federation // United Nations: [сайт].- Текст: электронный.-URL: https://population.un.org/wpp/Graphs/1_Demographic\%20Profiles/Russian\%20Federation. pdf.

13. World Population Prospects 2019. Demographic Profiles. Russian Federation // United Nations: [сайт].— Текст: электронный. - URL: https://population.un.org/wpp/Graphs/DemographicProfiles/Line/643.

14. Национальный проект «Демография» // Будущее России. Национальные проекты: [сайт].- Текст: электронный.- URL: https://futurerussia.gov.ru/demografiya.

15. Chernysheva N.A., Perskaya V.V., Petrov A.M., Bakulina A.A. GREEN ENERGY FOR BELT AND ROAD INITIATIVE: ECONOMIC ASPECTS TODAY AND IN THE FUTURE / International Journal of Energy Economics and Policy. 2019. T. 9. № 5. C. 178-185.

16. Kevorkova Z.A., Petrov A. M., Savina N. V. TOWARDS LIABILITIES OF CORPORATE SYSTEMS / International Journal of Civil Engineering and Technology. 2019. T. 10. № 2. C. 1582-1593.

17. Petrov A.M., NikiforovaE.V., Kiseleva N.P., Grishkina S.N., LihtarovaO.V. CREATION OF THE REPORTING ON SUSTAINABLE DEVELOPMENT OF COMPANIES BASED ON SOCIOECONOMIC MEASUREMENT STATISTICS / International Journal of Recent Technology and Engineering. 2019. T. 8. № 2. C. 4005-4012.

18. Sotnikova L.V., PolenovaS.N., Mislavskaya N.A., PetrovA.M., BasovaM.M. SUSTAINABLE DEVELOPMENT, MACRO AND MICRO LEVEL: RUSSIAN AND FOREIGN MODEL / International Journal of Recent Technology and Engineering. 2019. T. 8. № 2. C. 4524-4532.

19. Kosolapova M.V., Muravitskaya N.K., TolmachevM.N., Melnikova L.A., PetrovA.M. TECHNOLOGY FOR SOLVING THE PROBLEMS RELATED TO THE IMPLEMENTATION OF THE CONCEPT OF PRESERVING CAPITAL IN ACCOUNTING AND STATISTICS / International Journal of Recent Technology and Engineering. 2019. T. 8. № 3. C. 789-792.

20. Kosolapova M.V., PetrovA.M., YshanovI.G., Muravitskaya N.K., NurmuhamedovaH.S. THE ECONOMIC SIGNIFICANCE OF STATISTICAL RESEARCH ACTIVITIES OF REPRESENTATIVE OFFICES OF COMPANIES ABROAD / International Journal of Innovative Technology and Exploring Engineering. 2019. T. 8. № 10. C. 27132722.

21. Petrov A.M., Yurasova I. O., Putihin Y.E., Poluleh M. V., Erohina V.N. ACCOUNTANT MODELING TECHNOLOGY AND STATISTICS IN THE CONTEXT OF THE NEW EDUCATIONAL CONCEPT / International Journal of Innovative Technology and Exploring Engineering. 2019. T. 8. № 12. C. 3214-3217. 
22. Petrov A.M., Kiseleva N.P., KevorkovaZ.A., MelnikovaL.A., YshanovI.G. PRESENT DEVELOPMENT PRACTICES FOR TAX, FINANCIAL AND STATISTICAL REPORTING IN THE RUSSIAN FEDERATION / International Journal of Innovative Technology and Exploring Engineering. 2019. T. 8. № 12. C. 3538-3542.

23. Karpova T.P., Petrov A. M., Antonova O. V. DIRECTIONS OF ACCOUNTING DEVELOPMENT IN THE CONDITIONS OF DIGITALIZATION / Journal of Advanced Research in Dynamical and Control Systems. 2018. T. 10. № 7 Special Issue. C. 117-125.

24. Lymar M.P., Kevorkova Z.A., Petrov A. M.THE CONVERGENCE OF NATIONAL AND INTERNATIONAL ACCOUNTING STANDARDS: CHINESE EXPERIENCE / International Journal of Civil Engineering and Technology. 2018. T. 9. № 13. С. $82-94$.

25. Бабаев Ю.А., Друцкая М.В., Кеворкова Ж. А., Листопад Е. Е., Петров А. М. БУХГАЛТЕРСКИЙ УЧЕТ, АНАЛИЗ И АУДИТ ВНЕШНЕЭКОНОМИЧЕСКОЙ ДЕЯТЕЛЬНОСТИ / Учебник для студентов обучающихся по специальности 080109 «Бухгалтерский учет, анализ и аудит» / под редакцией Ю. А. Бабаева. Москва, 2010.

26. Петров А.М., ПолоусЕ.А. ПОВЫШЕНИЕ ТРАНСПАРЕНТНОСТИ ПОКАЗАТЕЛЯ ДЕБИТОРСКОЙ ЗАДОЛЖЕННОСТИ В ОТЧЕТНОСТИ / Международный бухгалтерский учет. 2011. № 6 (156). С. 2 -12.

27. Карпова Т.П., Петров А. М., Горбаткова Г. А., Самарина Л. Б., Дашкина Г.Г., Сидорова М. И., Сабанин Р. Л., Ситникова В.А., Листопад Е.Е. БУХГАЛТЕРСКИЙ УЧЕТ В СФЕРЕ УСЛУГ / учебник дЛя студентов высшего профессионального образования, обучающихся по специальности 080109 «Бухгалтерский учет, анализ и аудит» / Под редакцией М.А. Вахрушиной; Москва, 2011. Сер. Читай

28. Петров А.М., МельнИковаЛ.А. ФОРМИРОВАНИЕ ОТЧЕТНОСТИ В СООТВЕТСТВИИ С ТРЕБОВАНИЯМИ МСФО КАК ОБЪЕКТИВНАЯ НЕОБХОДИМОСТЬ НА СОВРЕМЕННОМ ЭТАПЕ РАЗВИТИЯ ЭКОНОМИКИ РФ / Проблемы современной экономики. 2017. № 2 (62). С. 105-107.

29. ТЕОРИЯ БУХГАЛТЕРСКОГО УЧЕТА / учебник / Ю.А.Бабаев, А. М.Петров; под ред. Ю.А.Бабаева. Москва, Проспект, 2011. (Изд. 5-е, перераб. и доп.)

30. Петров А.М. ОБЩЕСТВЕННОЕ ПИТАНИЕ 6 в 1: учетная политика, документооборот, калькулирование себестоимости, бухгалтерский учет, налоги, отчетность / А. М. Петров. Москва, 2011. Сер. Полное руководство бухгалтера 